\title{
Hubungan antara Kedalaman Permukaan Air Tanah dengan Salinitas di Pesisir Pantai Kungkai Baru serta Penggunaan Model Discovery Learning
}

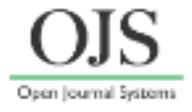

\author{
Sutijo Joko Sudiro ${ }^{1 *}$, Muchammad Farid ${ }^{2}$ dan Eko Swistoro ${ }^{3}$ \\ ${ }^{1}$ Pascasarjana Pendidikan IPA FKIP Universitas Bengkulu \\ ${ }^{2}$ Jurusan Fisika FMIPA Universitas Bengkulu \\ ${ }^{3}$ Pendidikan Fisika FKIP Universitas Bengkulu \\ *Email: sutijobanget@gmail.com
}

\begin{abstract}
[Relationship between Groundwater Surface Depth with Salinity at the Coast of New Kungkai Beach and its Implementation on Discovery Learning Model]. The aims of this study were 1) to describe the relationship between groundwater surface depth with salinity in the coastal areas of new kungkai beach of Seluma, and 2) to determine the improvement of learning outcomes (cognitive) of high ability students, moderate and low by using discovery learning model on the concept of static fluid in class $X$ computer and network engineering at SMK Negeri 3 Seluma. This research was a quasi experimental research with one groups pretest-posttest design. The results showed: 1) The relationship between depth with salinity has a value of 0.6478 with a significance level of 0.001 (<0.05); 2) Learning with discovery learning model can improve student learning outcomes on cognitive aspects (knowledge). Increased cognitive results can be seen from the average value of the initial test, the final test and the average value of gain in the class $x$ Tkj is high-ability groups are at high criteria with a value of 0.75 gain in the group is in the criteria medium with the value of gain 0,52 and in the low group were in moderate criteria with a gain value of 0.44. There is a difference in learning outcomes between the high, medium and low groups. The difference is shown by Fcount > Ftable $(4.04>3.35)$ with a significance level of $5 \%$.
\end{abstract}

Keywords: Groundwater surface depth; salinity; discovery learning model; SMKN 3 Seluma.

\begin{abstract}
ABSTRAK
Penelitian ini bertujuan untuk: 1) mendeskripsikan hubungan antara kedalaman permukaan air tanah dengan salinitas di pesisir pantai Desa Kungkai Baru Kecamatan Air Periukan Kabupaten Seluma,dan 2) menentukan peningkatan hasil belajar (kognitif) siswa berkemampuan tinggi, sedang dan rendah dengan menggunakan Model Discovery Learning pada konsep Fluida Statis di Kelas X Teknik Komputer dan Jaringan (TKJ) SMK Negeri 3 Seluma. Penelitian ini adalah penelitian quasi eksperimen dengan desain one groups pretest-posttest. Hasil penelitian menunjukkan: 1) Hubungan antara kedalaman dengan salinitas memiliki nilai 0,6478 dengan tingkat signifikansi $0,001(<0,05) ; 2)$ Pembelajaran dengan model discovery learning dapat meningkatkan hasil belajar siswa pada aspek kognitif (pengetahuan). Peningkatan hasil kognitif dapat dilihat dari nilai rata-rata tes awal, tes akhir dan nilai rata-rata gain pada kelas x Tkj yaitu kelompok berkemampuan tinggi berada pada kriteria tinggi dengan nilai gain 0,75 pada kelompok sedang berada pada kriteria sedang dengan nilai gain 0,52 dan pada kelompok rendah berada pada kriteria sedang dengan nilai gain 0,44. Terdapat perbedaan hasil belajar antara kelompok tinggi, sedang dan rendahterdapat perbedaan yang ditunjukkan dengan $F_{\text {hitung }}>F_{\text {tabel }}(4,04>3,35)$ dengan taraf signifikasi $5 \%$.
\end{abstract}

Kata kunci: Kedalaman permukaan air tanah; salinitas; model Discovery Learning; SMKN 3 Seluma. 


\section{PENDAHULUAN}

Wilayah Indonesia merupakan negara kepulauan yang sebagian besar wilayahnya terdiri atas lautan. Dengan bertambahnya jumlah penduduk di Indonesia maka bukan hanya daratan saja yang menjadi tempat tinggal namun daerah pesisir pantai juga mulai menjadi tempat tinggal sebagian penduduk Indonesia. Hal ini sebenarnya kurang baik bagi kesehatan, dikarenakan air di daerah pesisir sangat dipengaruhi oleh keadaan air laut disekitarnya, sehingga sangat beresiko bagi warga yang tinggal disekitar pesisir.

Pemerintah Kabupaten Seluma berdiri pada tahun 2003 Bila ditinjau dari letak garis bujur dan lintangnya berada pada koordinat 0349'55'66" LS - 04'21'40'22" LS dan $101^{\circ} 17^{\prime} 27^{\prime}$ 57' BT - 102 59'40'54” BT dan secara geografis wilayah Kabupaten Seluma. Pesisir Pantai Kungkai Baru berada di Desa Kungkai Baru Kecamatan Air Periukan Kabupaten Seluma Provinsi Bengkulu. Sebagian besar masyarakat desa Kungkai Baru memiliki mata pencarian Berkebun dan bertani, sedangkan untuk memenuhi kebutuhan air bersih, masyarakat Desa Kungkai Baru masih memanfaatkan eksplorasi air tanah yang kondisinya masih terkontaminasi oleh air laut. Keadaan ini sudah berlangsung secara turun temurun sejak desa Kungkai baru terbentuk. Hal ini sebenarnya sangat beresiko bagi warga desa kungkai baru khususnya bagi para balita dan anak-anak yang masih memiliki imun tubuh yang lemah. Jika kadar garam yang terkandung dalam air konsumsi warga melewati ambang batas normal maka dapat menimbulkan gejala penyakit yang berbahaya misalnya dapat meningkatkan kecendrungan hipertensi atau darah tinggi.

Air merupakan sumber kehidupan yang tidak dapat tergantikan oleh apa pun juga. Tanpa air manusia, hewan dan tanaman tidak akan dapat hidup. Ketersediaan sumberdaya air memegang peranan sangat penting untuk memenuhi kebutuhan berbagai sektor pembangunan. Dengan pertumbuhan jumlah penduduk yang semakin meningkat membuat masyarakat di wilayah pesisir Seluma menjadikan permintaan akan sumber air permukaan dan air tanah juga meningkat, baik https://ejournal.unib.ac.id/index.php/pendipa digunakan untuk keperluan sehari - hari seperti mandi, keperluan rumah tangga bahkan untuk air minum. Secara tidak langsung air laut akan mempengaruhi air tanah dikarenakan wilayah Desa Kungkai Baru merupakan kawasan pesisir yang sangat dekat dengan lautan. Hal ini menyebabkan peneliti tertarik untuk melakukan studi tentang pengaruh tinggi permukaan air tanah dengan salinitas air di wilayah pesisir seluma. Belum adanya penelitian yang dilakukan di daerah ini terutama yang berhubungan dengan kedalaman permukaan air tanah dengan salinitas air di daerah pesisir Seluma menjadikan satu hal yang menarik untuk diteliti. Penelitian mengenai kualitas air tanah pernah dilakukan oleh Septianingsih et al (2018) dan didapatkan hasil bahwa hubungan antara kualitas air dari segi kekeruhan dengan kedalaman muka air tanah memiliki hubungan yang "kuat", sehingga dapat dikatakan terdapat kecenderungan hubungan terbalik antara kualitas air dan muka air tanah segi kekeruhan.

Setelah penelitian sains maka akan dilanjutkan dengan menerapkannya di sekolah. Sekolah yang akan dijadikan tempat penelitian pendidikan adalah SMK Negeri 3 Seluma. Berdasarkan pengalaman mengajar selama tiga tahun di SMK Negri 3 Seluma diketahui bahwa faktor utama penyebab rendahnya hasil belajar dan kurangnya pemahaman konsep Fisika oleh siswa di sekolah ini adalah guru kurang menerapkan metode pembelajaran yang variatif dan menarik, serta guru juga kurang memanfatkan sumber belajar yang tersedia dilingkungan sekolah. Dalam menyampaikan materi guru cenderung menggunakan metode pembelajaran ekspositori sehingga pengalaman belajar yang diperoleh di kelas tidak utuh dan tidak berorientasi tercapainya kompetensi inti dan kompetensi dasar, Ini terlihat dari nilai ratarata hasil Ulangan Semester ganjil tahun pelajaran 2016/2017 hanya 60 dengan nilai tertinggi 90 dan nilai terendah 30. Nilai rata-rata ini tergolong masih rendah.

Pembelajaran lebih bersifat teachercentered, guru menyampaikan konsep fisika sebagai produk dan siswa menghafal informasi faktual. Siswa mempelajari Fisika pada domain kognitif yang terendah dan tidak dibiasakan untuk mengembangkan afektif dan psikomotornya. Fakta di kelas menunjukkan 
bahwa banyak siswa yang cenderung tidak mau berfikir secara mandiri. Cara berfikir yang dikembangkan dalam kegiatan belajar belum menyentuh domain afektif dan psikomotor.

Berdasarkan latar belakang di atas maka peneliti tertarik untuk melakukan penelitian di SMK Negeri 3 Seluma. Penelitian ini berjudul Hubungan Antara Kedalaman Permukaan Air Di Pesisir Pantai Kungkai Baru Dengan Salinitas Air Sumur Masyarakat Serta Efektivitas Penggunaan Model Discovery Learning Terhadap Hasil Belajar Di SMK Negeri 3 Seluma.

\section{METODE PENELITIAN}

Ada dua jenis penelitian yang telah dilakukan. Jenis penelitian yang pertama adalah penelitian sains yang bertujuan menjelaskan hubungan antara salinitas dengan kedalaman air tanah di pesisir pantai Kungkai Baru. Penelitian yang kedua adalah penelitian pendidikan. Penelitian pendidikan ini merupakan jenis penelitian quasi eksperimen dengan desain One Groups Pretest-Posttest terhadap pelaksanaan pembelajaran menggunakan Model Discovery Learning untuk meningkatkan hasil belajar siswa. Penelitian sains dilaksanakan pada bulan Februari s.d Maret 2017, Sedangkan tempat penelitiannya di Pesisir Pantai Kungkai Baru Kecamatan Air Periukan Kabupaten Seluma Provinsi Bengkulu.

Dalam penelitian pendidikan yang menjadi populasi penelitian yang diteliti adalah seluruh siswa kelas X SMK Negeri 3 Seluma tahun ajaran 2016/2017. Banyaknya subjek yang akan diteliti adalah 245 siswa yang terdiri dari 7 kelas dan yang menjadi sampel adalah kelas $\mathrm{X}$ Teknik Komputer dan Jaringan (TKJ) sebanyak 30 Siswa.

Menurut Arikunto (2008), siswa diberi tes awal terlebih dahulu, kemudian dilakukan pembelajaran menggunakan Model Discovery Learning (DL) sehingga pada akhirnya diberikan tes akhir. Penelitian menggunakan model Discovery Learning (DL) juga dilakukan oleh Wicaksana dan Usodo (2016) dengan pendekatan Saintifik, mengenai pengembangan kemampuan komunikasi dan disposisi matematik oleh Qodariyah dan Hendriana, (2015), mengenai pengembangan Lembar
Kerja Siswa (LKS) Berorientasi Model Pembelajaran Discovery Learning (Dl) oleh Setiadewi et al (2015), dan lain-lain. Tes awal dan tes akhir dilaksanakan dengan menggunakan tes yang sama. Desainnya dapat dilihat seperti Tabel 1.

Tabel 1. Desain penelitian

\begin{tabular}{|c|c|c|c|}
\hline Kelompok & Pretest & Perlakuan & Posttest \\
\hline Eksperimen & $\mathrm{O}$ & $\mathrm{X}$ & $\mathrm{O}$ \\
\hline
\end{tabular}

Keterangan:

$\mathrm{O}=$ Pretest dan Posttest

$\mathrm{X}=$ Perlakuan model pembelajaran Discovery Learning

Instrumen penelitian terdiri atas perangkat pembelajaran (RPP dan LKS) dan instrumen pengumpulan data (soal pretest dan posttest sebanyak 10 soal). Sebelum digunakan, semua instrumen tersebut dilakukan uji validitas. Menurut Sugiyono (2009) valid berarti instrumen tersebut dapat digunakan untuk mengukur apa yang seharusnya diukur. Data penelitian ini berupa hasil belajar kognitif.Data tersebut dianalisis dengan statistik deskriptif dan Uji Anava Satu Jalur (One Way Anava).

\section{HASIL DAN PEMBAHASAN}

Penelitian mengenai hubungan antara kedalaman permukaan air tanah di pesisir pantai Kungkai Baru dengan salinitas air sumur masyarakat serta penggunaan metode Discovery Learning terhadap hasil belajar di SMK Negeri 3 Seluma menggunakan instrumen penelitian berupa pretest dan posttest. Penelitian sains dilaksanakan pada bulan Maret 2017 di Pesisir Pantai Kungkai Baru Kecamatan Air Periukan Kabupaten Seluma Propinsi Bengkulu. Penelitian ini menggunakan geolistrik untuk melihat kedalaman permukaan air dan struktur lapisan tanah sedangkan untuk mengukur salinitas menggunakan alat salinometer.Pada penelitian ini, digunakan 6 lintasan yang masing-masing lintasan memiliki panjang bentangan $100 \mathrm{~m}$ dengan jumlah sampel sebanyak 10 sumur. 
Tabel 2. Kedalaman dan Salinitas

\begin{tabular}{|c|c|c|}
\hline \multirow{2}{*}{ Nama Sampel } & \multicolumn{2}{|c|}{ Skor Nilai Parameter } \\
\cline { 2 - 3 } & kedalaman $(\mathbf{m})$ & $\begin{array}{c}\text { salinitas } \\
\text { (mg/l) }\end{array}$ \\
\hline LINTASAN 1 & 5,51 & 0,002 \\
\hline LINTASAN 2 & 6,51 & 0,002 \\
\hline LINTASAN 3 & 3,66 & 0,003 \\
\hline LINTASAN 4 & 5,99 & 0,002 \\
\hline LINTASAN 5 & 16,66 & 0,001 \\
\hline LINTASAN 6 & 14,16 & 0,001 \\
\hline
\end{tabular}

Dari hasil analisis data uji korelasi menggunakan microsoft exel 2007 diperoleh hungungan antara kedalaman dengan salinitas memiliki nilai 0,6478 dengan tingkat signifikansi $\quad 0,001 \quad(<0,05) . \quad$ Koefisien determinasi antara kedalaman dan salinitas semakin mendekati nilai satu yaitu 0,6478 . Hal ini menunjukkan bahwa $64,78 \%$ variabel dependen yaitu salinitas dapat dipengaruhi variabel independen yaitu kedalaman sumur, sedangkan $35,22 \%$ dijelaskan oleh faktor ataupun variabel lainnya (variabel independen lainnya di luar model). Kualitas air asin atau payau tidak layak untuk dijadikan bahan baku air minum. Aliran air tanah sangat mempengaruhi kondisi daerah pantai, karena aliran ini menjaga keseimbangan antara air laut dan air tanah. Pengambilan air tanah (baik sumur dangkal maupun sumur dalam) secara tidak teratur akan berdampak pada jumlah air bersih yang mengalir ke laut akan berkurang, sehingga keseimbangan antara air laut dan air tawar terganggu. Akibatnya, intrusi air laut akan lebih berkembang ke hilir.

Instrumen yang digunakan untuk penelitian yaitu berupa soal pretest dan soal posttest. Soal pretest diberikan diawal pembelajaran, selanjutnya diberikan pembelajaran dengan menggunkan model Discovery Learning. Pada akhir pembelajaran diakukan evaluasi berupa posttest untuk melihat peningkatan hasil belajar. Berdasarkan hasil tes awal dan akhir pada kelas eksperimen diperoleh hasil yang ditunjukkan pada Gambar 1 dan 2 .

Dari data di atas dapat dideskripsikan bahwa implementasi dari penelitian sains dengan model pembelajaran Discovery Learning (DL), dapat meningkatkan hasil belajar siswa.

https://ejournal.unib.ac.id/index.php/pendipa

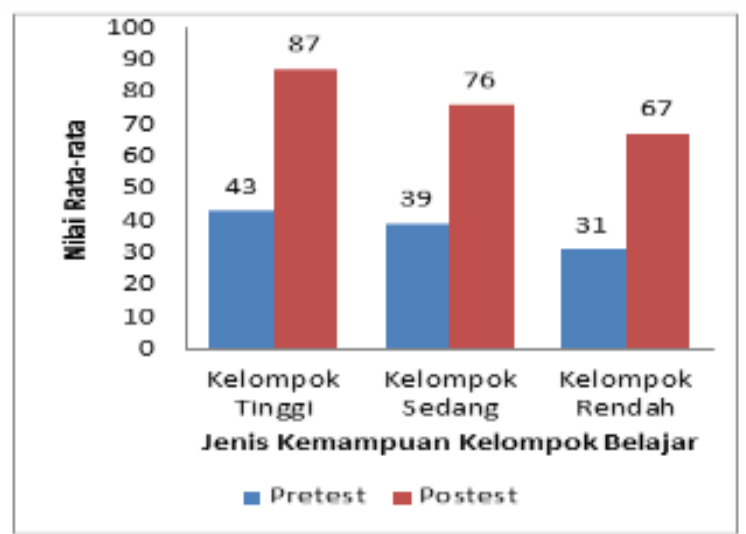

Gambar 1. Diagram batang nilai rata-rata pretest dan posttest

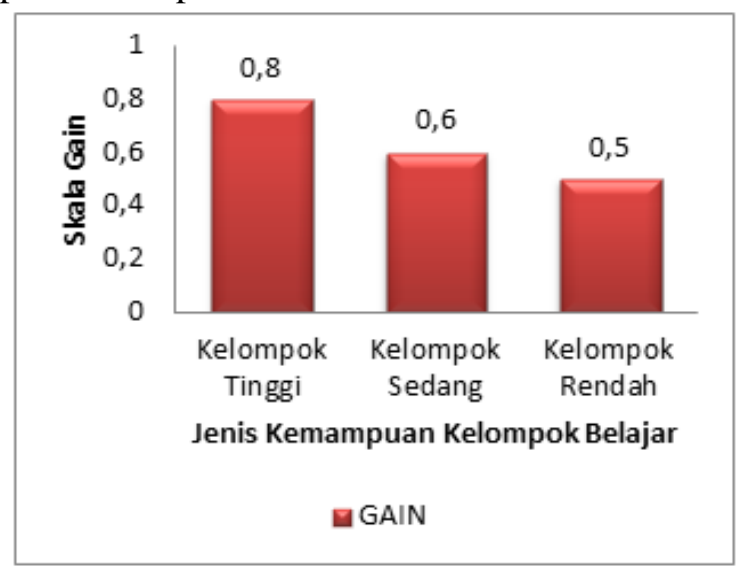

Gambar 2. Diagram batang N-Gain Nilai Pretest dan Posttest

Hal ini terlihat pada peningkatan rata-rata hasil pretest dan postest serta terlihat juga pada nilai kriteria uji gain. Gain dalam penelitian ini merupakan perubahan kemampuan yang dimiliki siswa setelah mengikuti pembelajaran. Perubahan yang terjadi sebelum dan sesudah pembelajaran dihitung dengan rumus $\mathrm{g}$ faktor $\left(\mathrm{N}_{\text {-gain }}\right)$ yang dikembangkan oleh Hake dalam Suardani, (2014). Menurut Putrayasa (2014) menyimpulkan bahwa Model Discovery Learning (DL) dapat meningkatkan hasil belajar siswa dan berpengaruh terhadap hasil belajar IPA.

Pada kelompok belajar tinggi berada pada kriteria gain tinggi bernilai 0,8 dan kelompok belajar sedang bernilai gain 0,5 serta kelompok belajar rendah berada pada nilai gain 0,4. Kriteria gain kelompok belajar tinggi berada pada kriteria gain tinggi sedangkan kelompok belajar sedang dan rendah berada pada kriteria gain sedang. Dengan $\mathrm{dk}$ pembilang $8 \mathrm{dan} \mathrm{dk}$ 
penyebut 8 , maka $\mathrm{F}_{\text {tabel }}$ pada taraf signifikansi adalah 3,44. Dari hasil perhitungan nilai $\operatorname{Varian}\left(\mathrm{F}_{\text {hitung }}\right)$ diperoleh skor 1,76 . Nilai ini selanjutnya akan dibandingkan dengan Nilai $\mathrm{F}_{\text {tabel. }}$ Ternyata $\mathrm{F}_{\text {hitung }}$ lebih kecil dari $\mathrm{F}_{\text {tabel }}(1,76<$ $3,44)$. Dengan demikian dapat disimpulkan bahwa varian data yang dianalisis homogen sehingga perhitungan analisi menggunakan Anava dapat dilanjutkan.

\section{KESIMPULAN}

Hubungan antara kedalaman dengan salinitas memiliki nilai 0,6478 dengan tingkat signifikansi $0,001(<0,05)$. Hasil analisa data ini memiliki tingkat korelasi yang sangat kuat. Pembelajaran dengan Model Discovery Learning (DL) dapat meningkatkan hasil belajar siswa pada aspek kognitif (pengetahuan). Peningkatan Hasil kognitif dapat dilihat dari nilai rata-rata tes awal, tes akhir dan nilai rata-rata gain pada kelas $\mathrm{X}$ TKJ yaitu kelompok Tinggi berada pada kriteria tinggi dengan nilai gain 0,75 pada kelompok sedang berada pada kriteria sedang dengan nilai gain 0,52 dan pada kelompok rendah berada pada kriteria sedang dengan nilai gain 0,44. Pembelajaran dengan Model Discovery Learning (DL) setelah diuji Anava Satu Jalur (One Way Anava) diperoleh $\mathrm{F}_{\text {hitung }}$ Lebih besar dari $\mathrm{F}_{\text {tabel }}(4,04>3,35)$, maka hipotesis alternatif $\left(\mathrm{H}_{\mathrm{a}}\right)$ diterima. Berarti terdapat perbedaan hasil belajar antara kelompok tinggi, Sedang dan rendah. Sehingga hipotesis diterima.

\section{DAFTAR PUSTAKA}

Arikunto, S. 2008. Dasar-Dasar Evaluasi Pendidikan. Jakarta: Bumi Aksara.

Putrayasa, I. M., Syahruddin, S. P., \& Margunayasa, I. G. 2014. Pengaruh Model Pembelajaran Discovery Learning dan Minat Belajar terhadap Hasil Belajar IPA
Siswa. MIMBAR PGSD Undiksha, 2(1).

Qodariyah, L., \& Hendriana, H. 2015. Mengembangkan Kemampuan Komunikasi dan Disposisi Matematik Siswa SMP melalui Learning. Edusentris, 2(3), 241-252.

Septianingsih, D. A., Firdaus, M. L., \& Farid, M. 2018. Pengukuran Kualitas dan Muka Air Tanah Di Sekitar Pt. Bio Nusantara Teknologi Untuk Mendukung Proses Pembelajaran Fisika. Pendipa Journal of Science Education, 2(1).

Setiadewi, F. S., Suryawati, E. S., \& Mahadi, I. M. 2015. Pengembangan Lembar Kerja Siswa (LKS) Berorientasi Model Pembelajaran Discovery Learning (Dl) untuk Meningkatkan Kemampuan Berfikir Kreatif Siswa pada Materi Bioteknologi Kelas XII SMA. Jurnal Online Mahasiswa Fakultas Keguruan dan Ilmu Pendidikan Universitas Riau, 2(2), 1-13.

Suardani, N. N., Swasta, I. B. J., Si, M., Widiyanti, N. L. P. M., \& Si, S. 2014. Pengaruh Model Pembelajaran Berbasis Masalah terhadap Kemampuan Pemecahan Masalah dan Keterampilan Proses Sains Siswa. Jurnal Pendidikan dan Pembelajaran IPA Indonesia, 4(1).

Sugiyono. 2009. Metode Penelitian Administrasi. Bandung: Alfabeta

Wicaksana, H., \& Usodo, B. 2016. Eksperimentasi Model Pembelajaran Problem Based Learning (PBL) dan Discovery Learning (DL) dengan Pendekatan Saintifik Pada Materi himpunan Ditinjau Dari Adversity Quotient (AQ) Siswa. Jurnal Pembelajaran Matematika, 4(3). 